\title{
Numerical Study of Initial Soil Moisture Impacts on Regional Surface Climate
}

\author{
Xueli Shi \\ National Climate Center, China Meteorological Administration, Beijing, China \\ E-mail: shixl@cma.gov.cn \\ Received July 8, 2011; revised August 16, 2011; accepted August 29, 2011
}

\begin{abstract}
In this paper, the impacts of initial soil moisture (SM) over the Huaihe River Basin of China on the summertime climate have been investigated with a regional climate model. Three fourth-month-long simulations are made for two summers, the abnormal flooding in 2003 and normal climate in 2004. Besides control simulations (noted as CTL), sensitivity experiments have been conducted by assigning the initial soil moisture equals to $50 \%$ and $150 \%$ of the simulated soil moisture while keeping the others unchanged, which are noted as SM50 and SM150, respectively. The results show that effects of initial SM anomalies at late spring can last for the whole summer, and the increase of initial soil moisture (SM150) has more significant effects than the decreased one (SM50). The differences between sensitivity experiments and CTL mainly appear at surface and near-surface atmosphere. When increasing the initial SM, the latent heat flux and surface soil moisture are increased, correspondingly the sensible heat flux, temperature and radiation are all decreased. The changes of rainfall are not distinct between SM50 and SM150, which might be related to the processes within atmosphere, especially the humidity pattern.
\end{abstract}

Keywords: Soil Moisture, Surface Climate, Model Simulation, Huaihe River Basin Component

\section{Introduction}

As a widely recognized low-pass filter, the soil moisture (SM) plays an important role in the interactions between land and atmosphere [1-3]. Liu (2003) suggested that SM might be more important in monthly and seasonal variability at regional scales [4]. Eltahir (1998) showed the key roles of SM in regulating the precipitation anomaly through the radiation and dynamic feedback on an observation basis [5].

But because of the lack in systematic measurements of long-term SM, most studies with observed datasets are locally confined. As an effective and unique compensation, numerical models have been widely used to investtigate the SM roles in predictions/simulations at various space-time scales over different regions. Results have shown that the SM has complex interactions with atmosphere and climate, and the feedbacks are not always consistent with different models and regions [6-8].

The Huaihe River Basin (HRB) region is one of the prominent political and economic regions of China, therefore the rainfall/flood prediction, control and prevention here is of extreme importance. Ma et al. (2000) has analyzed the observed relationship between SM and rainfall, and shown somewhat positive feedbacks between them [9]. Sun et al. (2005) also found positive correlation with the previous or concurrent rainfall, but negative with the subsequent rainfall a half year later [10]. With the land surface models, Lin et al. (2001) studied the initial SM effects on land surface processes via sensitivity experiments [11].

In this paper, initial SM effects on the subsequent climate will be further tested with a regional climate model. Two cases are selected, i.e., abnormal flooding year of 2003 and normal year of 2004, which are necessary to find some common SM effects in different years and relative processes involved. The numerical model and experiment configuration introductions are given in section 2. The model simulation and sensitivity experiment results are, respectively, presented in sections 3 and 4 . Finally is the summary and discussion in section 5.

\section{The Numerical Model and Experimental Configurations}

The regional climate model of National Climate Center 
(RegCM_NCC) is used for the study, detailed infor- mation about the model can be referred to Ding et al. (2008) [12] and Chow et al. (2008) [13]. The model has a 45-km horizontal resolution, with 105 and 85 grid numbers, respectively, in latitudinal and longitudinal direc- tions. The large-scale datasets are from the NCEP/NCAR Reanalysis II $\left(2.5^{\circ} \times 2.5^{\circ}\right)$ with 6 -hr interval [14]. The integration period is from 1 May to the end of August in each year.

Besides control simulations (noted as "CTL"), two sets of sensitivity experiments have been made, by modifying the initial SM into $50 \%$ and $150 \%$ over the broad HRB region $\left(105^{\circ} \mathrm{N}-120^{\circ} \mathrm{E}, 30^{\circ} \mathrm{N}-37^{\circ} \mathrm{N}\right)$, which are noted as SM50 and SM150. The initial SM is not the one at the right beginning, but the simulated SM at the last time slice for certain period (the 31st day), similar to Pielke et al. [1]. Except the initial SM, other configuretions are all same as CTL. And in order to keep the SM being within a reasonable range, the modified SM is confined within the range from the permanent wilting point to the field capacity.

In all the simulations, the first month is taken as the spin-up period, and the focus is on the climate features in the whole summer (June, July and August).

\section{Model Control Run Results}

The summer 2003 experienced abnormal climate at different regions around the world. In China, the HRB encountered the maximum rainfall and flooding since 1954, with about $50 \%$ larger than the normal at several provinces (such as the Jiangsu, Anhui and Henan), while 50\% less than the normal at provinces of south China (Jiangxi, Hunan and Guangxi provinces) (Figure 1).

To facilitate the interpretation of the results for sensitivity experiments, the control simulations of the 2003 summer are shown firstly. The observed precipitation is generally featured by the heavy rainfall centers at southwestern part of the model domain and the ocean near the Taiwan Island (Figure 2(a)). The model basically reproduced the pattern, but the rainfall is somewhat underestimated (overestimated) at the continental (costal and ocean) regions (Figure 2(b)).

The vertical profiles of zonal wind over HRB are shown in Figure 3. The westerly controls the higher troposphere in June, July and the second half of August above $700 \mathrm{hPa}$, with the strongest wind appearing at upper troposphere layers (Figure 3(a)), those are reasonably reproduced by in CTL simulation in both intensity and temporal evolution, such as the timing of the downward propagating of the westerly in the Middle of June and July (Figure 3(b)).

Therefore, the RCM has the capacity of reasonably reproducing the climate and weather features of both surface and atmosphere in summer 2003, it is suitable to the following sensitivity experiments.

\section{Effects of the Initial Soil Moisture}

The reanalyzed SM pattern at 31st May is featured by the centers located at the south and west of HRB (Figure 4(a)), which is generally consistent reproduced by the CTL simulation (Figuire 4(b)), but with certain difference in the "empirical" assigned SM (Figure 4(c)).

During JJA, the CTL and sensitivity experiments all show much of synoptic scale evolution, which are generally similar and consistent with each other, except certain magnitude differences (Figures omitted). So in this part, differences between sensitivity experiments and CTL will be analyzed to denote the initial SM effects, which can also avoid some impact due to the CTL simulation bias.

Observed Precipitation Anomaly Percentage of JJA 2003

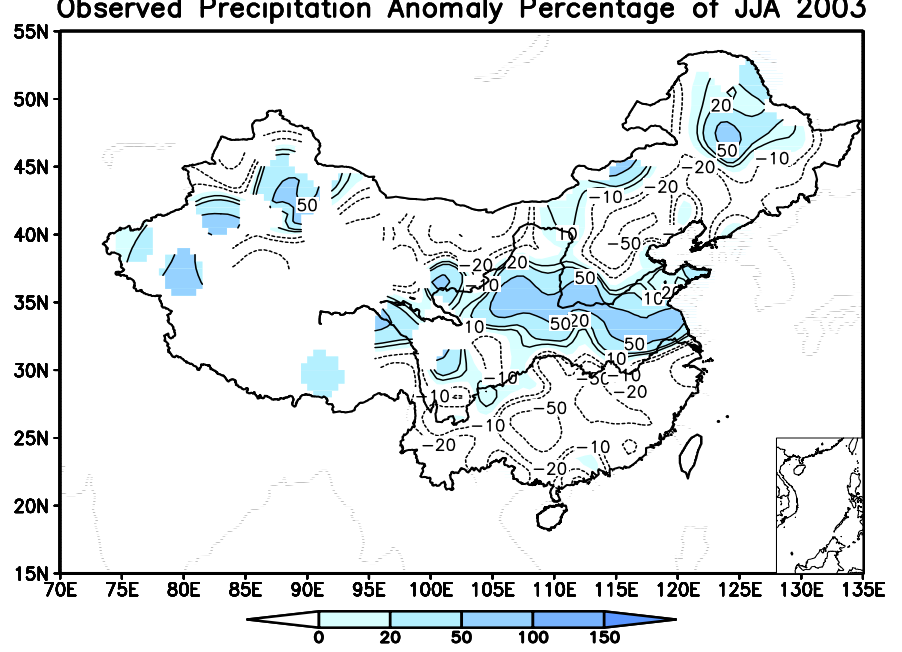

Figure 1. Observed precipitation abnormal (w.r.t. 1961-1990 climate, \%). 


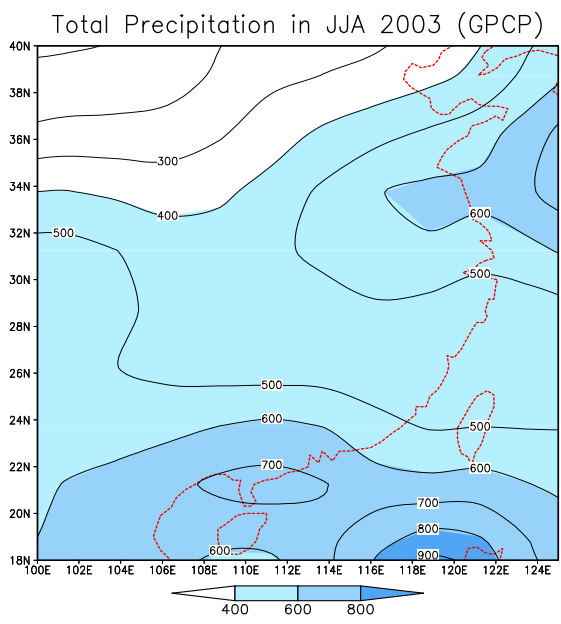

(a)

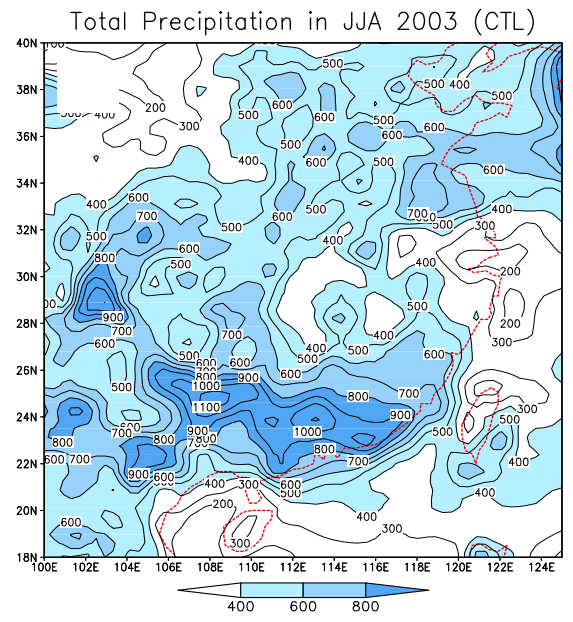

(b)

Figure 2. GPCP (a) and CTL simulated (b) precipitation in JJA 2003 (mm). Contour interval is $100 \mathrm{~mm}$. Rainfall amounts $\geq$ $400 \mathrm{~mm}$ are shaded.

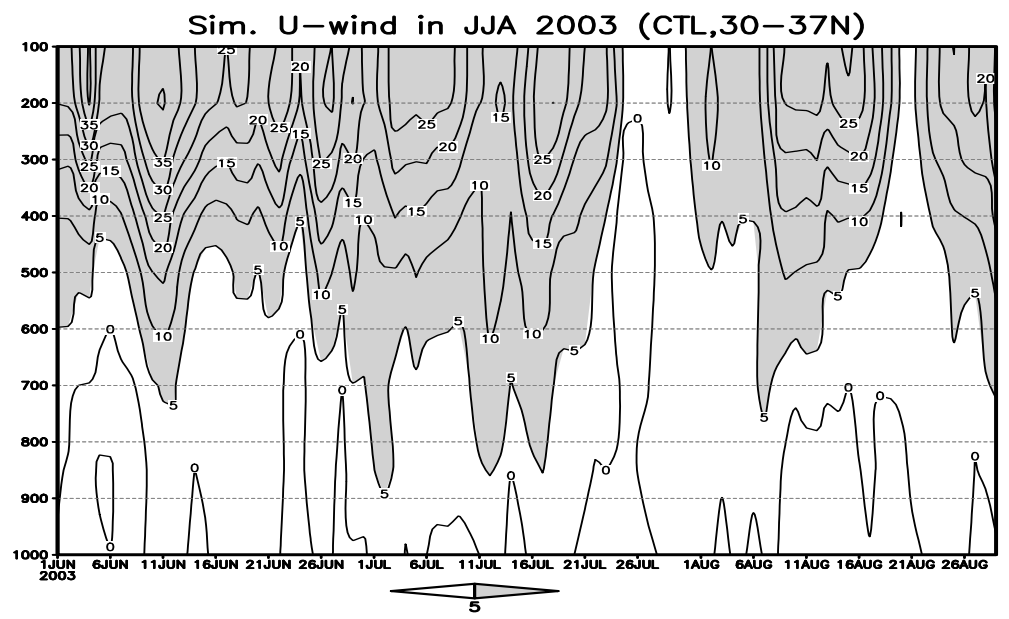

(a)

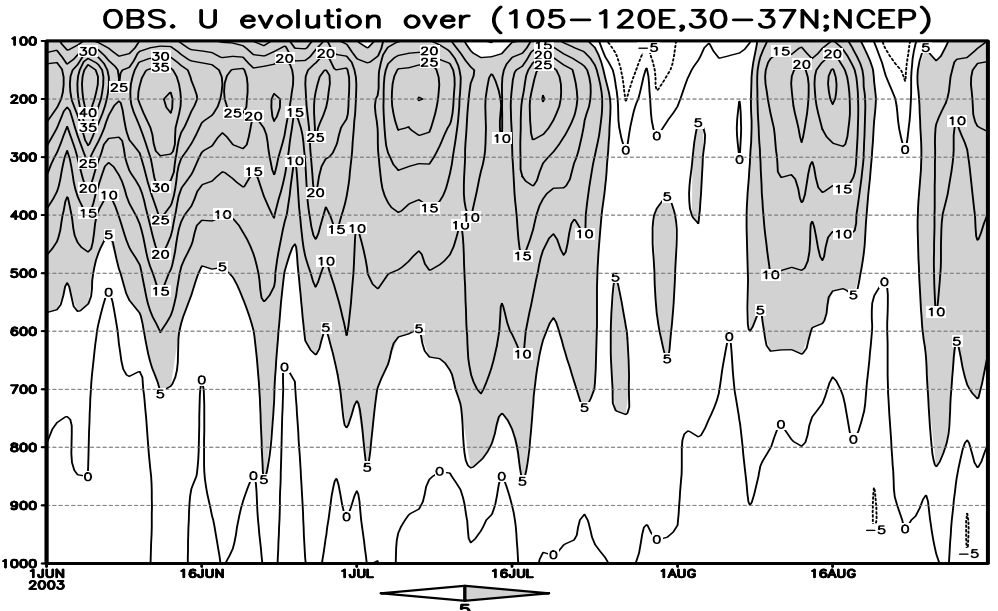

(b)

Figure 3. NCEP reanalyzed (a) and CTL simulated (b) regional mean zonal wind evolution in JJA $2003\left(\mathrm{~m} \cdot \mathrm{s}^{-1}\right)$. Contour interval is $5 \mathrm{~m} \cdot \mathrm{s}^{-1}$. Shaded represents wind $\geq 5 \mathrm{~m} \cdot \mathrm{s}^{-1}$. 


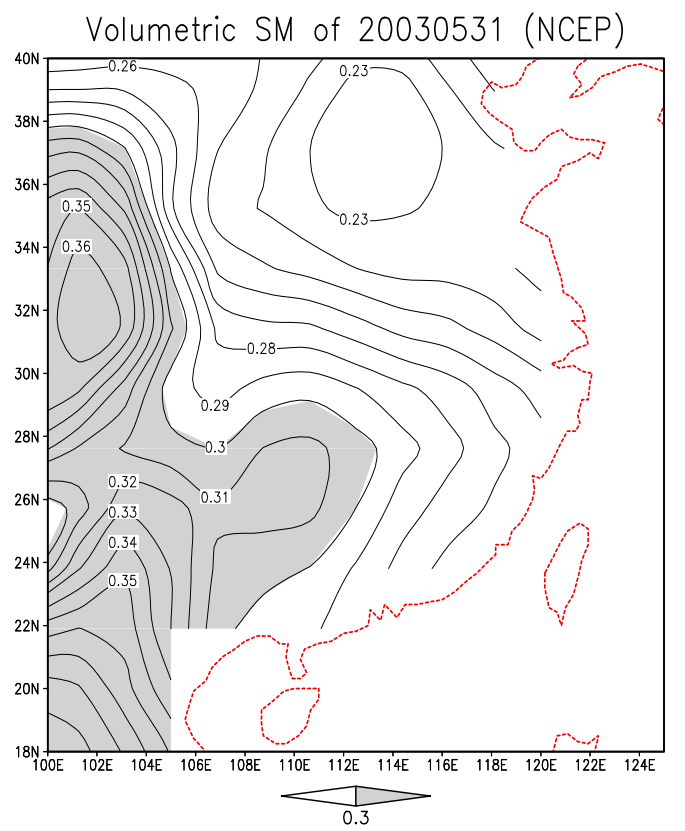

(a)

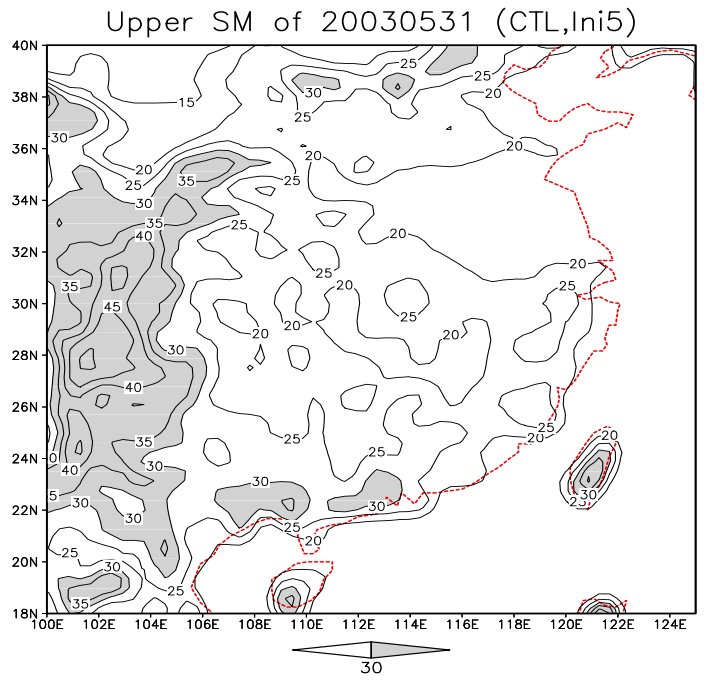

(b)

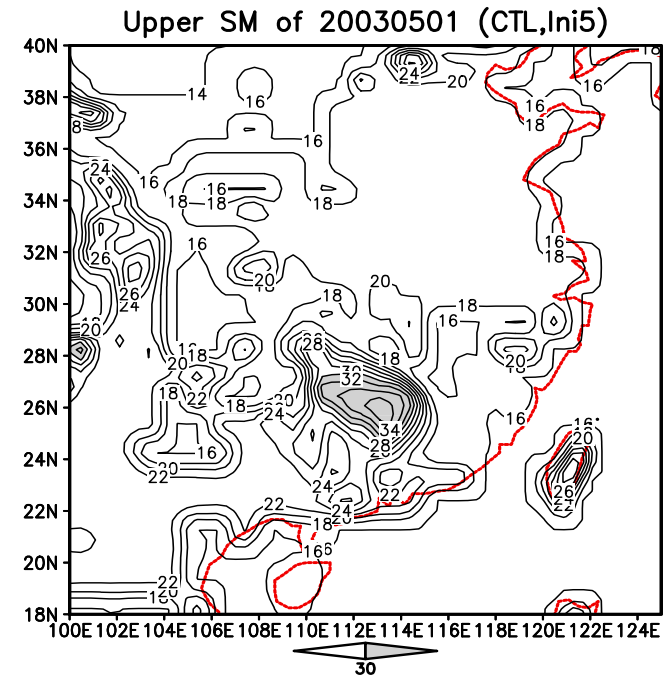

(c)

Figure 4. NCEP reanalyzed (a) and CTL simulated (b) soil moisture at 31 May of 2003, and CTL simulated at 1 st May 2003 (c). Unit of soil water in (a) and (b, c) is percentage and $\mathrm{mm}$, respectively Shaded area represents the magnitude $\geq 0.3$ and 30 mm.

Temporally, the wetting of SM causes the increase (decrease) of the latent (sensible) heat fluxes, with the magnitude being as large as $100(-80) \mathrm{W} \cdot \mathrm{m}^{-2}$ at the SM-changed area in SM150, but less change occurred in the SM50 (Figures 5(a)-(b)). As Hong and Pan (2000) [15] has pointed, one major role of SM is the partitioning of heat and latent fluxes in the surface energy budget, which affects the boundary layer development. With the change of surface heat flux, the surface temperature is obviously decreased (as low as $-5^{\circ} \mathrm{C}$ ) in the SM150, but not too much in SM50 (Figure 5(c)). Differences of the net upward long-wave radiation at surface follow the same patterns (Figure 5(d)). The SM of upper layer is increased in SM150 but less changed in SM50 (Figure 5(e)). The precipitation, however, is fluctuated in both SM150 and SM50 experiments, with relative larger from 20th June to 21st July, the episode of extensive and prolonged rainfall along the HRB (Figure 5(f)). Additionally, the differences are not decreased with time, and the largest departure appear at the middle July-almost two months later, which means that the impacts of the initial SM anomalies in mid-May can persist for the whole subsequent summer. 


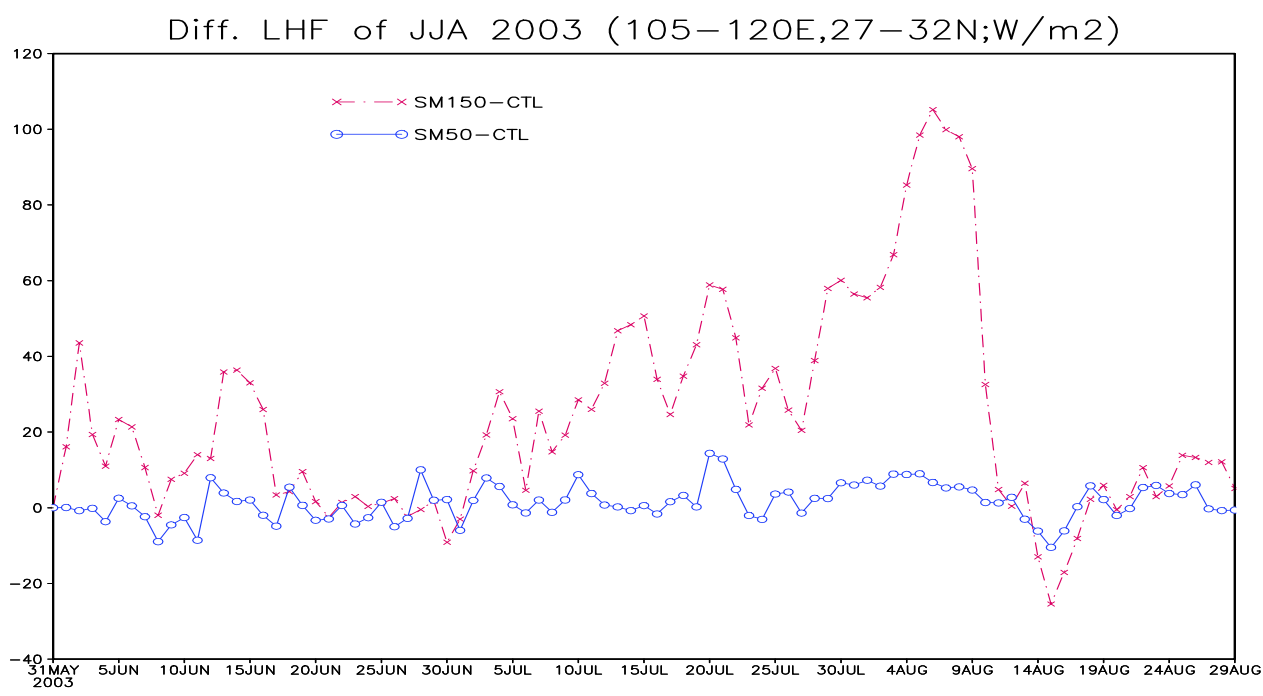

(a)

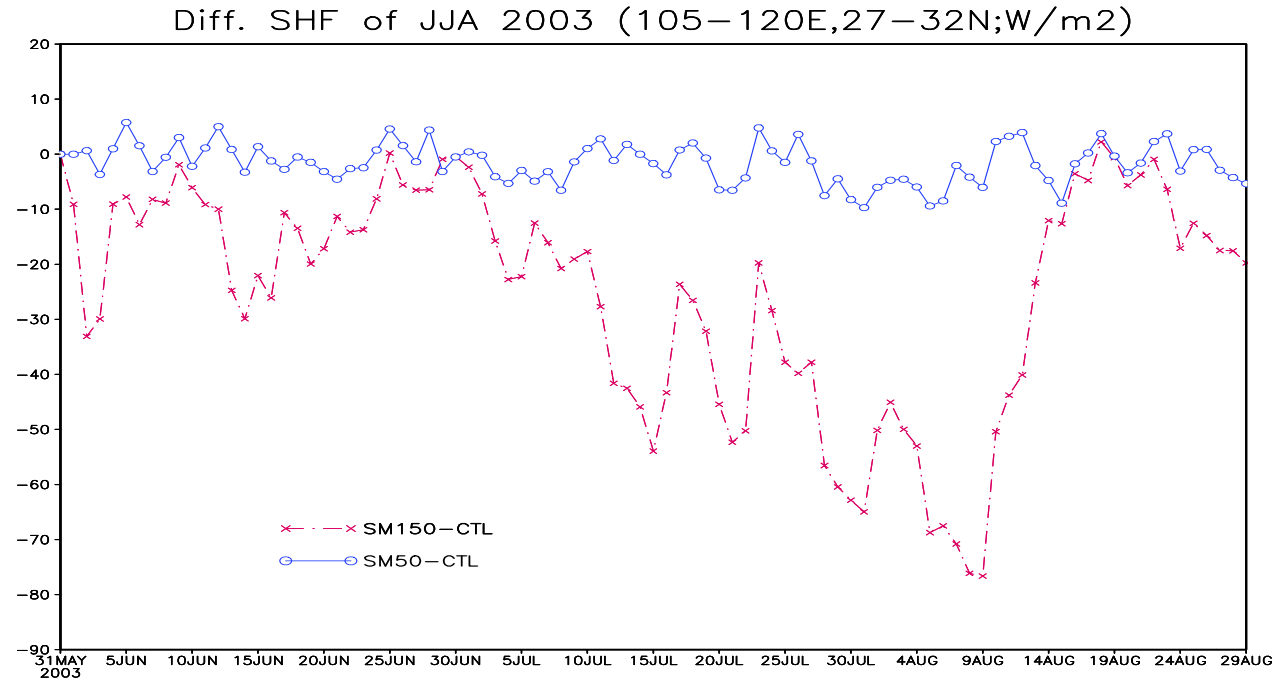

(b)

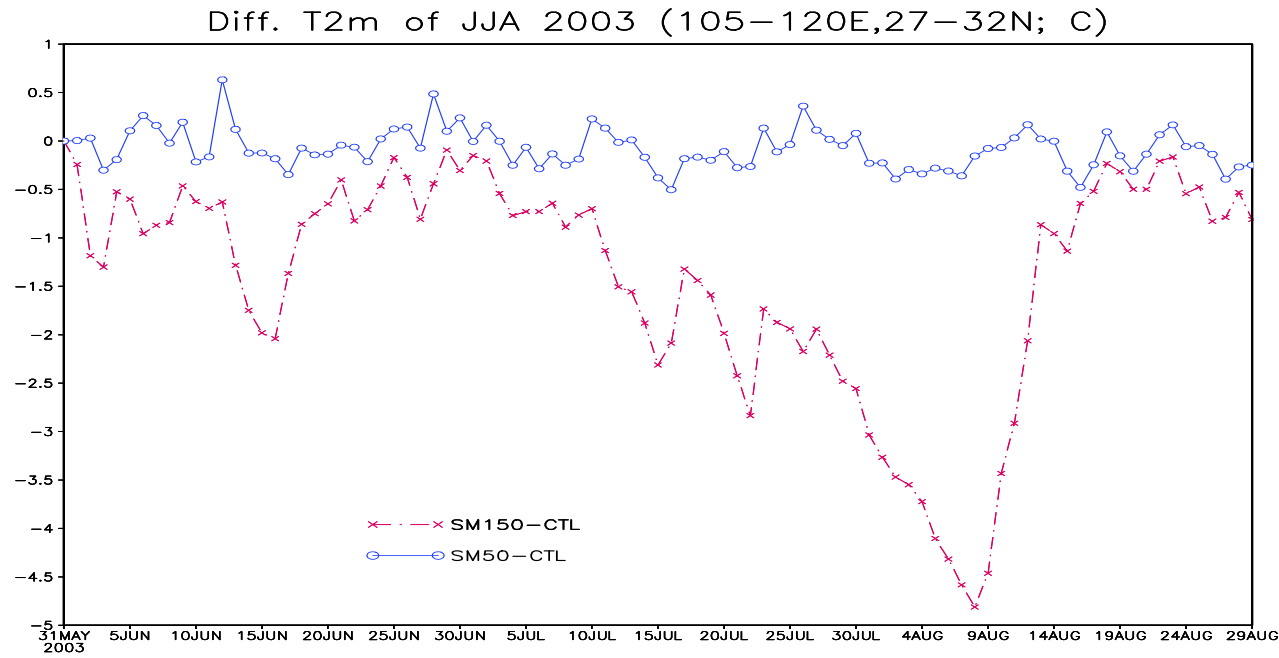

(c) 


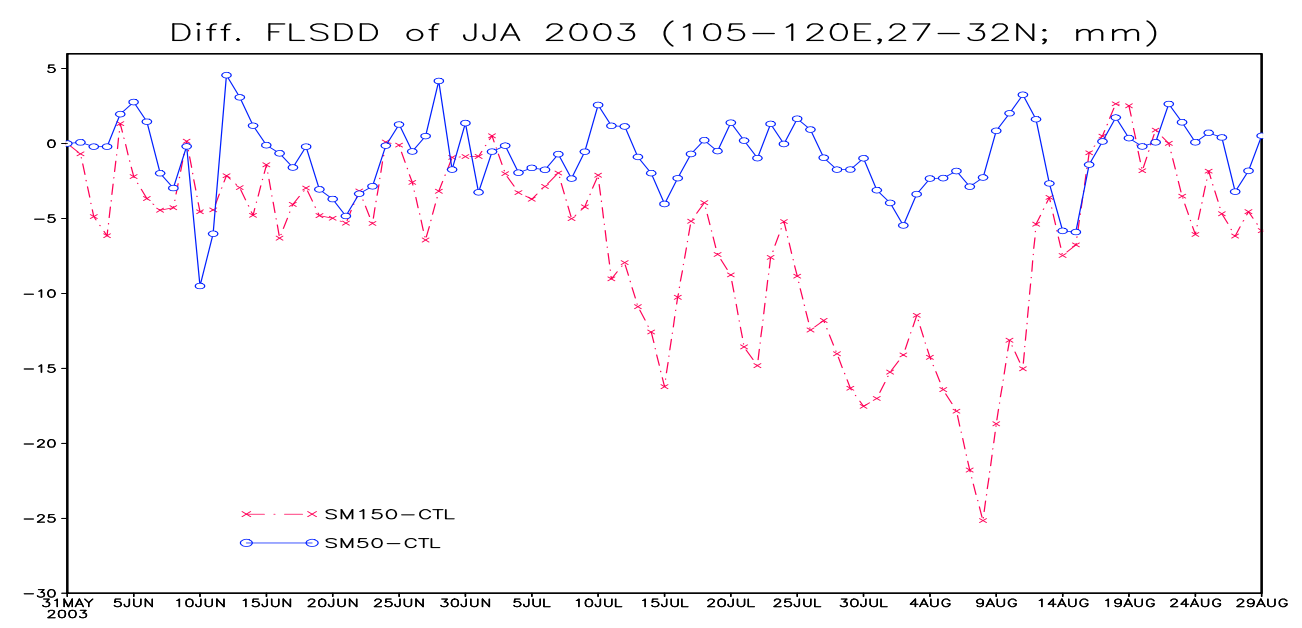

(d)

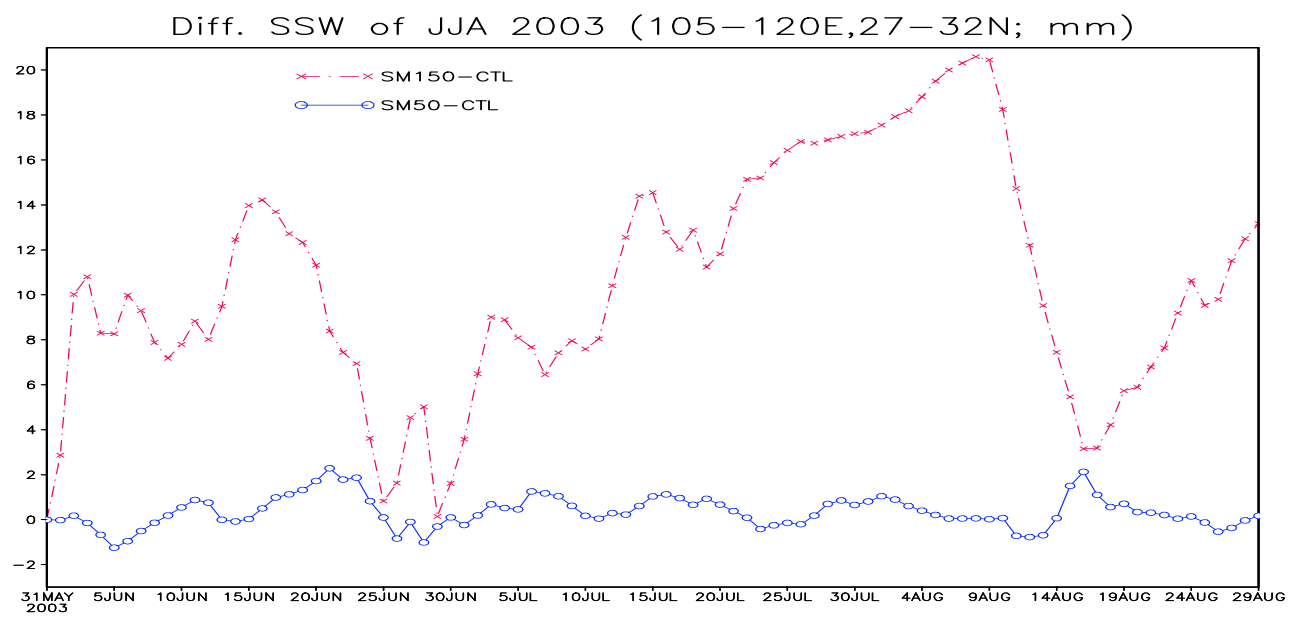

(e)

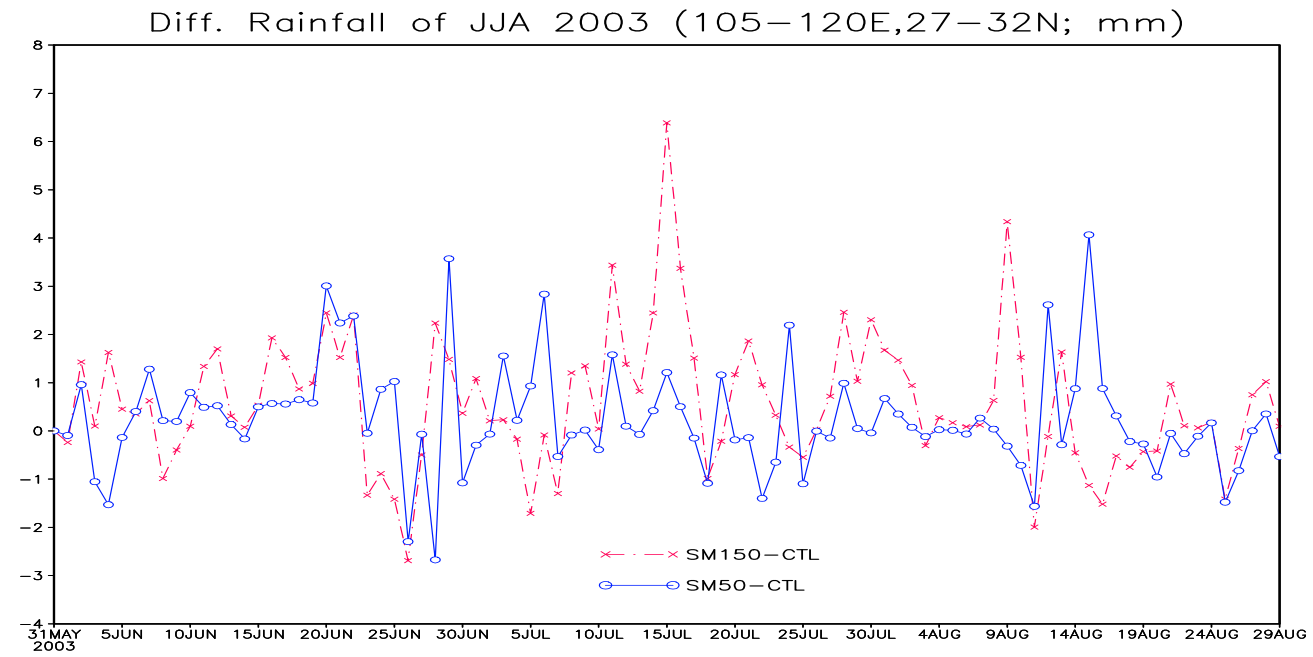

(f)

Figure 5. Differences between sensitivity experiments and CTL of summer 2003 for sensible (a) and latent (b) heat flux, surface temperature (c), radiation (d), surface layer soil moisture (e) and rainfall (f). Unit of heat flux and radiation is $W \cdot \mathrm{m}^{-2}$, temperature is ${ }^{\circ} \mathrm{C}$, rainfall and soil moisture are $\mathrm{mm}$ day $^{-1}$. Dashed line with cross: SM150-CTL, Solid line with circle: SM50-CTL. 
Spatially, with the wetting of initial SM, the latent heat flux (LHF) increases overwhelmed in East China (Figure 6(a)), and the sensible heat flux (SHF) is oppositely decreased in mostly SM-changed regions in SM150 (Figure 6(b)). There is an increase of rainfall at regions to the west and north of the SM-changed area in SM150 (Figure 6(c)). The changes in SM50 experiment are not so significant, but still show regional increased LHF and lessened SHF (Figures 6(c)-6(d)). The precipitation was mostly decrease at regions to the south of the Yangtze River Valley as well as the southwestern of the HRB, while increase north to the HRB in SM50 (Figure 6(f)). The different responses of sensible and latent heat fluxes are consistent with previous findings, but compared with CTL, the changes are larger in the SM-wetting experiment (SM150) than those in SM-drying one (SM50). It might be related to the fact that the actual soil water is actually much changed (increased) in SM150 than the decrease in SM50 sensible.
Figure 7 lists the vertical profile of differences between SM150 and CTL for various variables. The temperature is mostly decreased below $700 \mathrm{hPa}$, with the largest decrease being over $-5^{\circ} \mathrm{C}$ (Figure 7(a)). For the moisture (atmosphere humidity), the unique feature is the abnormal increase at the near surface layers below 850 $\mathrm{hPa}$, decrease between $500 \mathrm{hPa}-800 \mathrm{hPa}$, and some small positive anomalies at the upper layer above 500 $\mathrm{hPa}$, a sandwich-like pattern during the first half of June and from late July to the first half of August (Figure 7(b)). The zonal wind anomaly is positive (negative) at the lower (upper) levels during the two periods, and negative differences appeared at mid-troposphere from late July to 15th August (Figure 7(c)). The corresponding vertical motion is downward in the two periods (Figure 7(d)). The regional mean to the south of SMchanged area $\left(25^{\circ} \mathrm{N}-30^{\circ} \mathrm{N}, 110^{\circ} \mathrm{N}-120^{\circ} \mathrm{E}\right)$ is generally similar in pattern with those of HRB region (Figures omits).

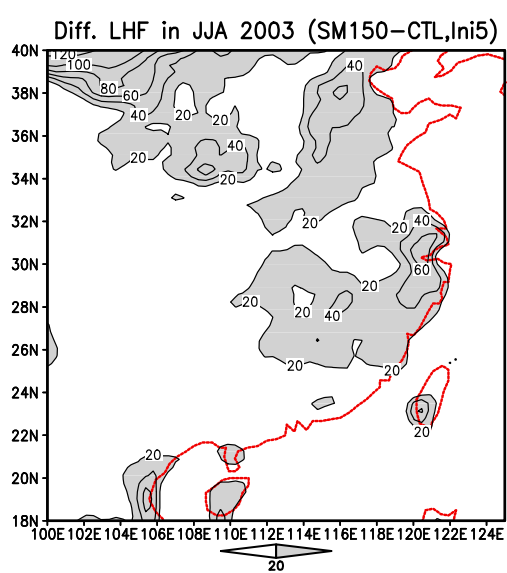

(a)

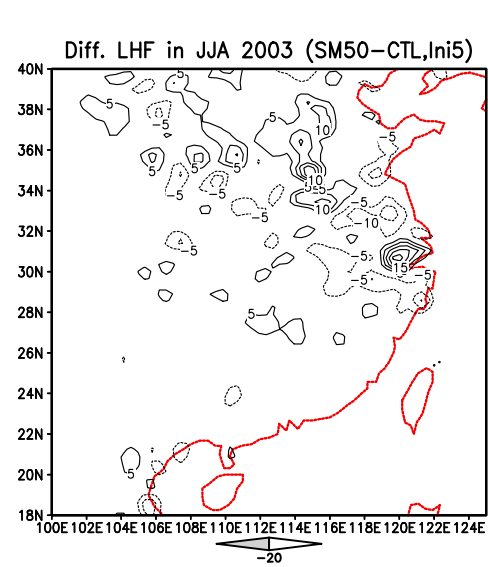

(d)

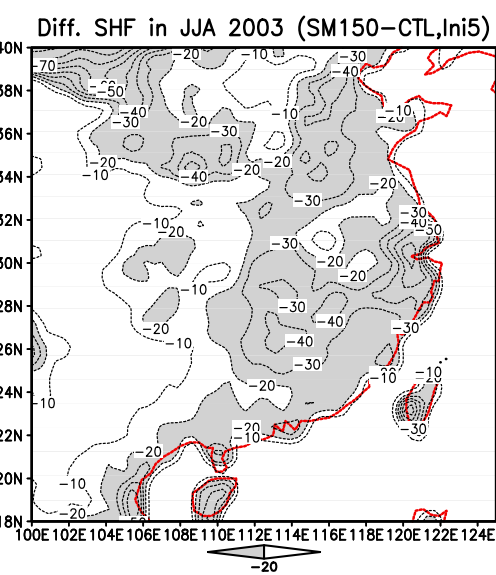

(b)

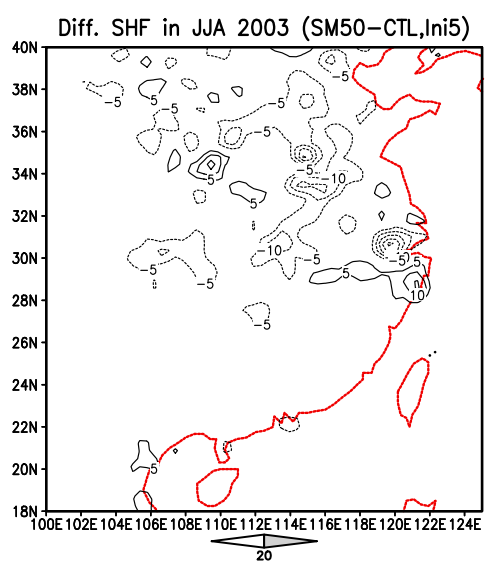

(e)

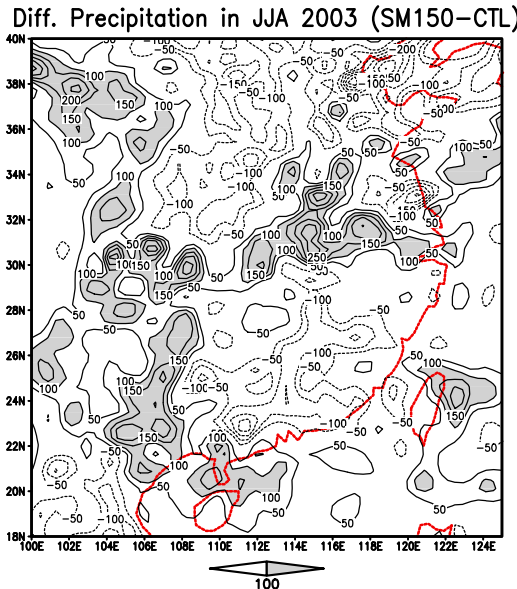

(c)

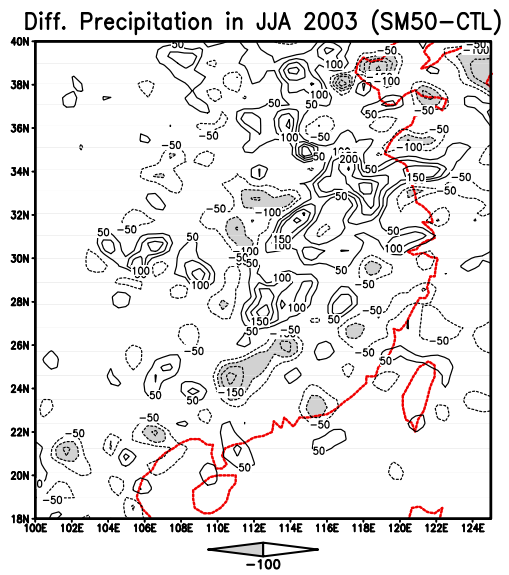

(f)

Figure 6. Spatial differences of latent heat flux (a-b), sensible heat flux (c-d) and precipitation (e-f) of SM150-CTL (left) and SM50-CTL (right) in JJA 2003. Unit of heat flux is $\mathrm{W} \cdot \mathrm{m}^{-2}$, precipitation is $\mathbf{m m}$. Shaded regions denote the heat flux $\geq 20$ $\mathrm{W} \cdot \mathrm{m}^{-2}$ in (a) and (c), $\leq-20 \mathrm{~W} \cdot \mathrm{m}^{-2}$ in (b) and (d), rainfall differences $\leq-100 \mathrm{~mm}$ in (e) and $\geq 100 \mathrm{~mm}$ in (f). 


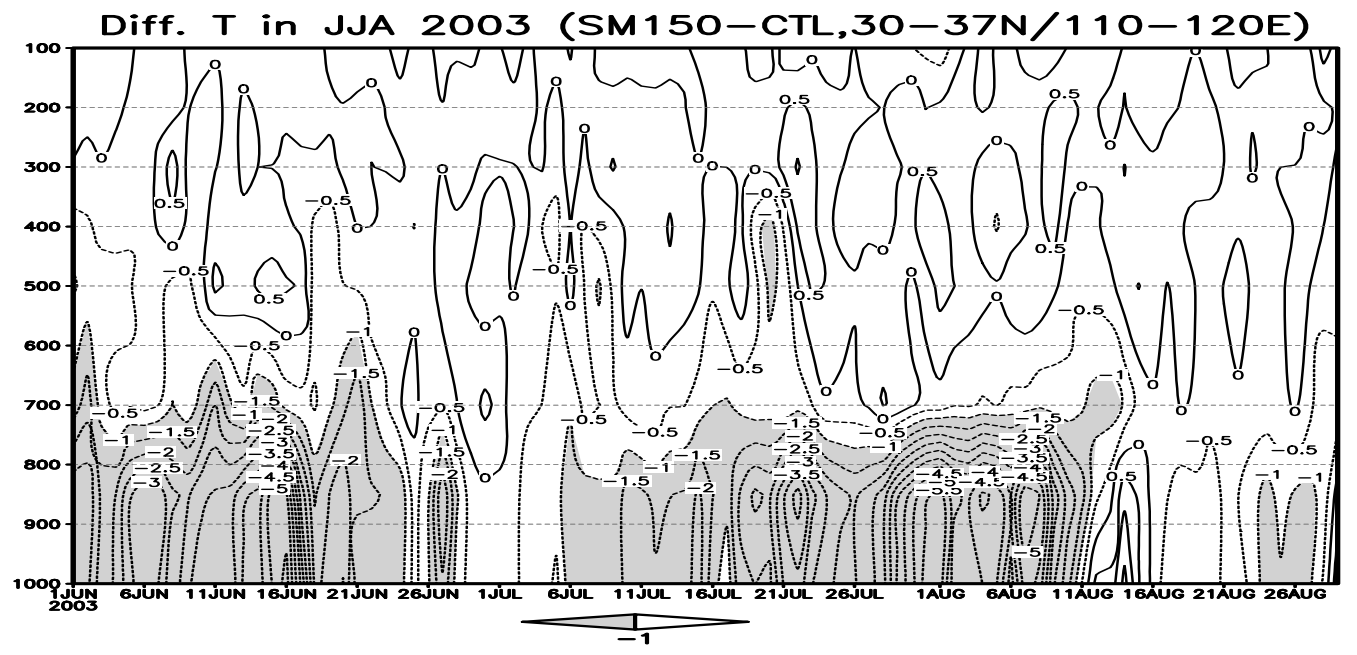

(a)

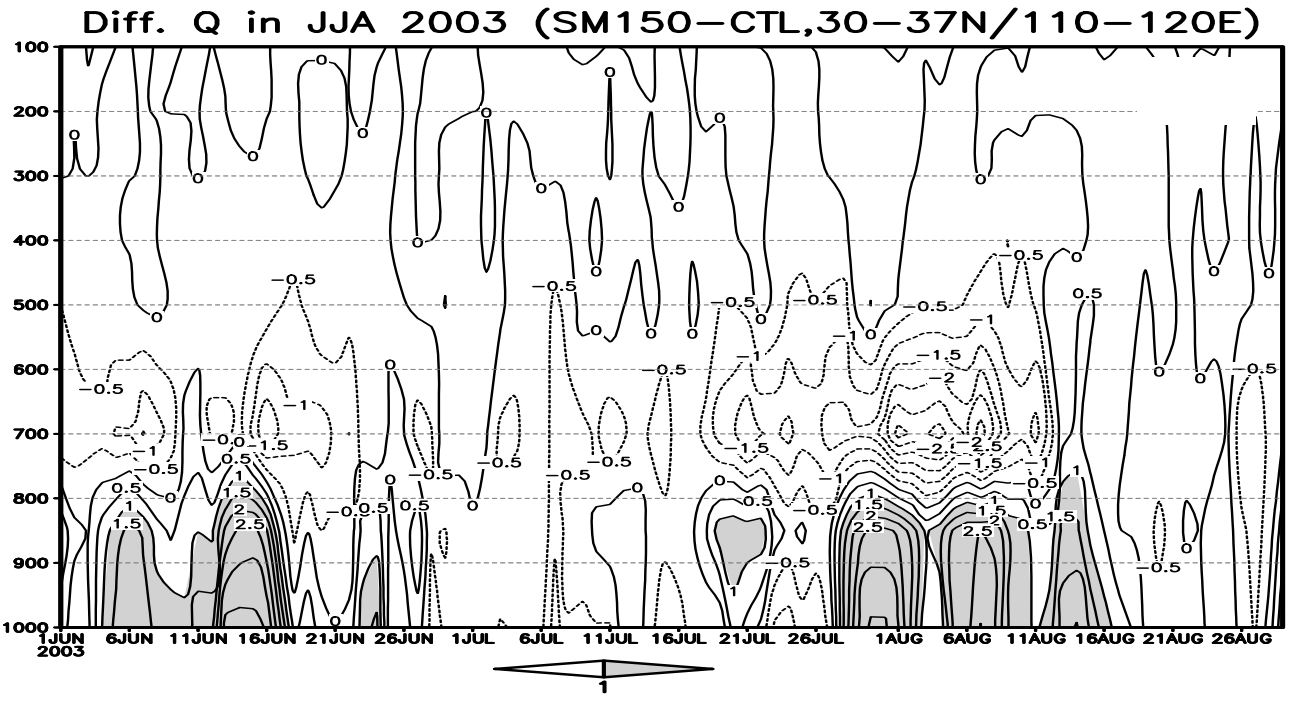

(b)

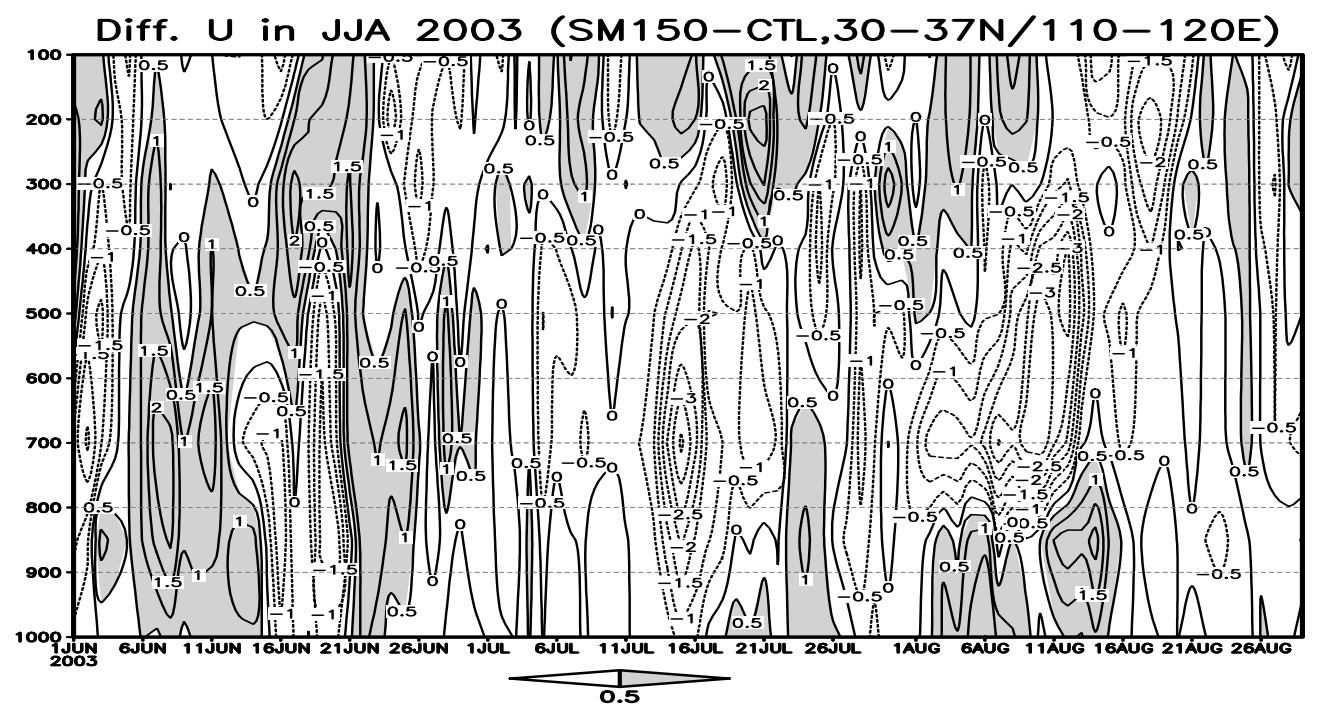

(c) 


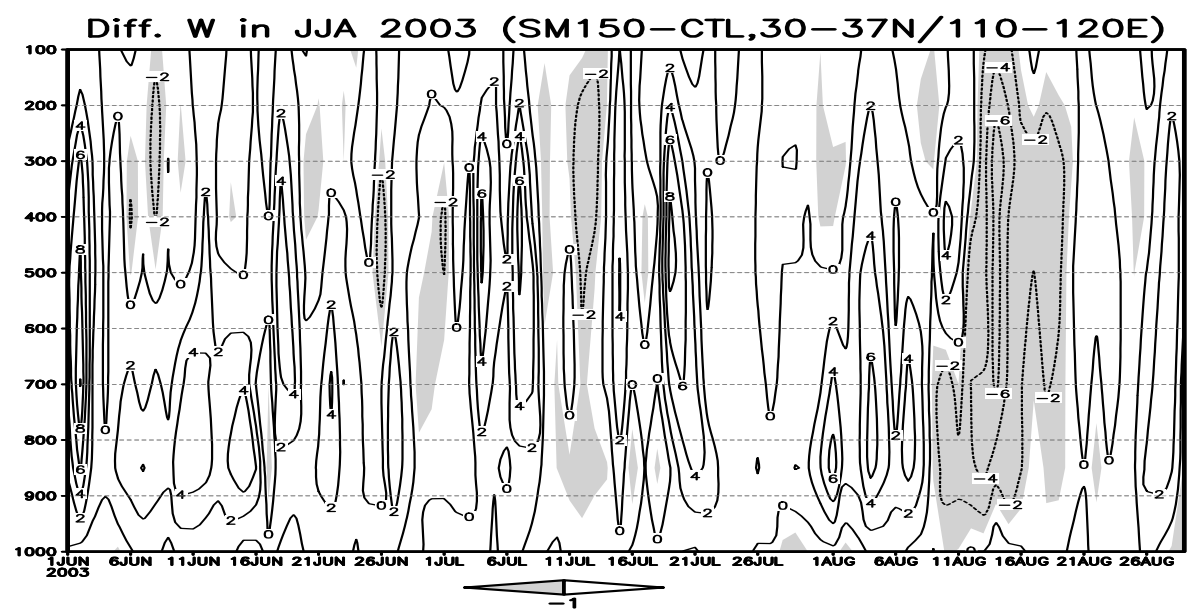

(d)

Figure 7. Regional mean vertical profiles of SM150-CTL over HRB in JJA 2003. (a): temperature ( $\left.{ }^{\circ} \mathrm{C}\right)$, (b): humidity $\left(\mathrm{kg}^{\mathrm{kg}}{ }^{-1}\right)$, (c) zonal wind $\left(\mathrm{m} \cdot \mathrm{s}^{-1}\right)$, (d): vertical velocity $\left(10^{-2} \mathrm{~Pa} \cdot \mathrm{s}^{-1}\right)$.

Horizontally the vector and convergence presented different features at different levels. It is overwhelmed anti-cyclonic circulation at $850 \mathrm{hPa}$, with large convergence appearing at regions to the south of and at the western part of SM-change area, which is favorable for the moisture gathering lower level (Figure 8(a)). At $700 \mathrm{hPa}$, although abnormal cyclonic circulation appeared at large model domain, but the convergence sparsely located to the west and north of the SM-changed region (Figure 8(b)). The $500 \mathrm{hPa}$ level was featured by cyclonic circulation and weaker convergence at the $\mathrm{HRB}$, and anti-cyclonic circulation to the south of HRB (Figure 8(c)). At $200 \mathrm{hPa}$, the anti-cyclonic circulation was dominant at broad regions, and the convergence belt located to the south of HRB (Figure 8(d)). This relative larger convergence at 850 and $200 \mathrm{hPa}$ might be the reason for the vertical moisture pattern, and needs further investigations.

Therefore significant impacts of the initial SM anomalies appear in the mid-lower troposphere in SM150. The wet (dry) SM experiments reveal cooling (warming) and moistening (drying) in the lower troposphere, indicating weak (strong) dry convection. But the rainfall differences and processes within atmosphere are not always opposite between SM150 and SM50 experiments.

\subsection{Differences in Summer 2004}

The seasonal mean differences of LHF and SHF between sensitivity experiments and CTL in summer 2004 show general similar patterns as in summer 2003 (Figures omitted). At to the rainfall, it is generally decreased to the north of and at the mid-north part of SM-changed area, as well as regions to the south of the Yangtze River Valley, and is slightly increased along the latitude-belt between $28^{\circ} \mathrm{N}-32^{\circ} \mathrm{N}$ in SM150 (Figure 9(a)). The precipitation differences are not too distinct in and outside the SM-changed area, although it is decreased at the mideastern part of HRB and part of South China. Increased rainfall appeared at the latitude belt of $28^{\circ} \mathrm{N}$ $32^{\circ} \mathrm{N}$ (Figure 9(b)), consistent with but not opposite to that in SM150.

The temporal evolutions of surface variables are generally consistent with those of summer 2003, with more prominent differences appearing at SM150 experiments than SM50, such as the increase (decrease) of latent (sensible) heat flux (Figures 10(a)-(b)), decrease of surface temperature (Figure 10(c)) and long wave radiation (Figure 10(d)), increase of surface soil water (Figure 10(e)). The rainfall differences are comparative between SM150 and SM50 (Figure 10(f)).

Therefore, initial SM modification can cause climate changes at surface and atmosphere, with the manners of impact being generally consistent in two cases. All of these seem to be related to heat flux (e.g. sensible heat flux and the latent heat flux as an index of evaporation). Particularly, when increasing the initial SM, the summer evaporation (LHF) is increased in regions at the south part of HRB and south to the mid-lower reaches of Yangtze River valley, while the SHF is decreased. This surface changes induced lower temperature and boundary layer mixing processes, as well as changes in the velocity and especially vertical moisture profiles. As to the rainfall, some locally changes occurred with the SM-change, but not too distinct in SM150 and SM50, which imply that SM did not affect rainfall via the direct impact of low-level atmosphere moisture from surface, but some more complex interactions within atmosphere, which need further studies. 


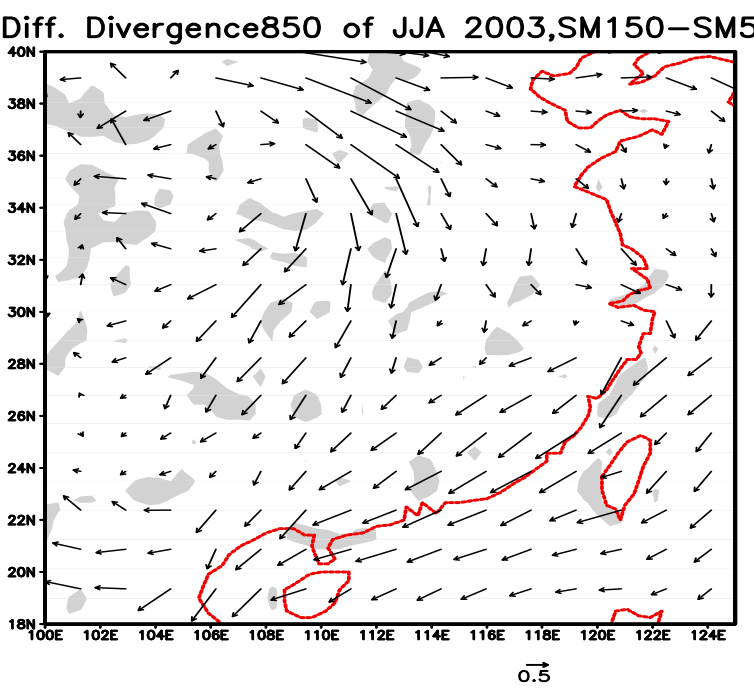

(a)

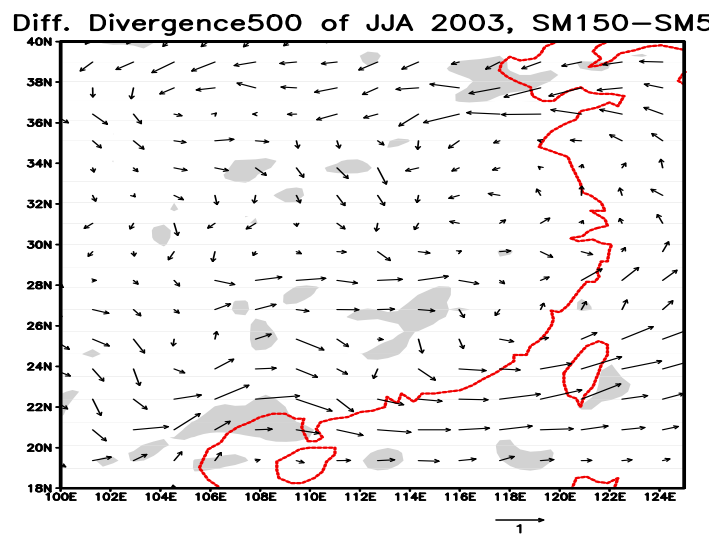

(c)

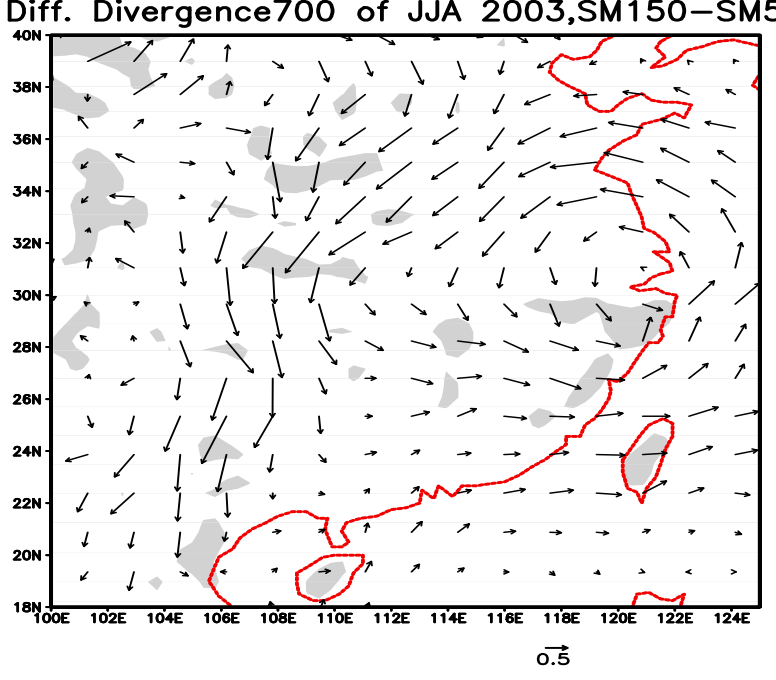

(b)

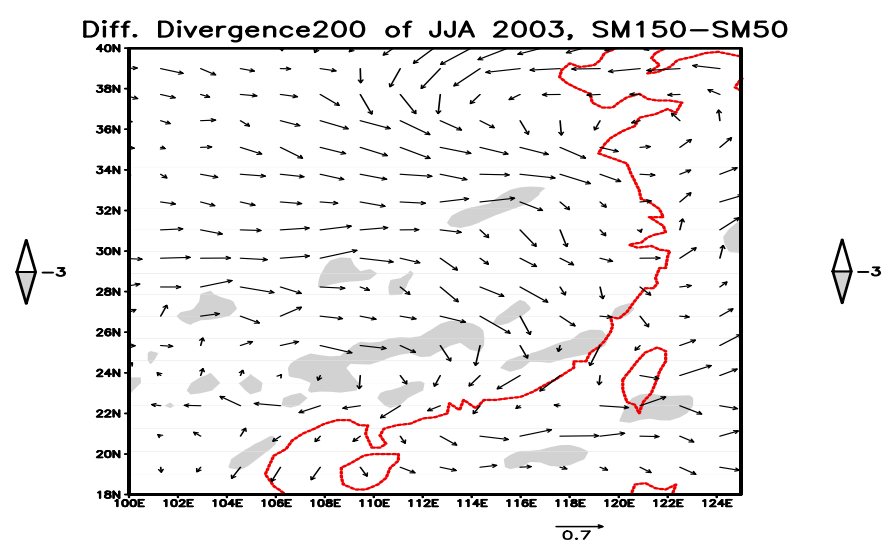

(d)

Figure 8. Horizontal distribution of UV-vector and divergence (shaded, <-3. e-5 s $\mathrm{s}^{-1}$ ) at 850 (a), 700 (b), 500 (c) and 200 (d) hPa. Units of vector and divergence is, respectively, $\mathrm{m} \cdot \mathrm{s}^{-1}$ and $1 . \mathrm{e}-5 \mathrm{~s}^{-1}$.

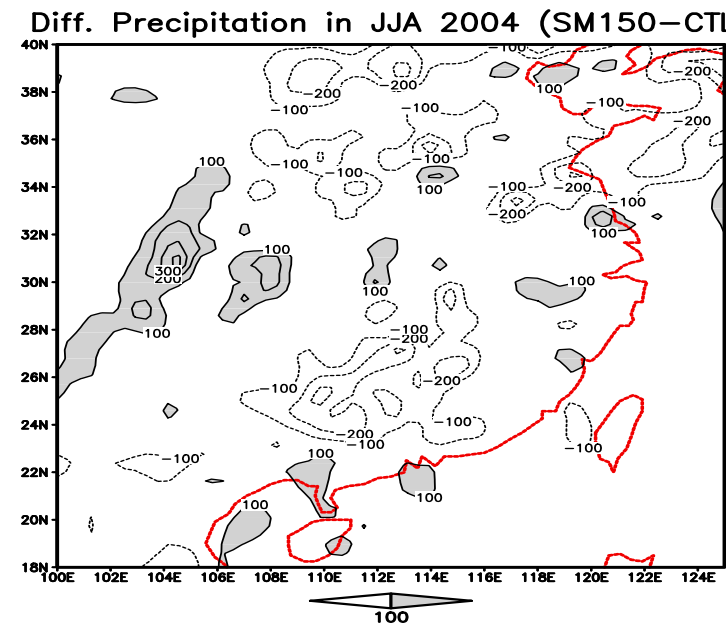

(a)

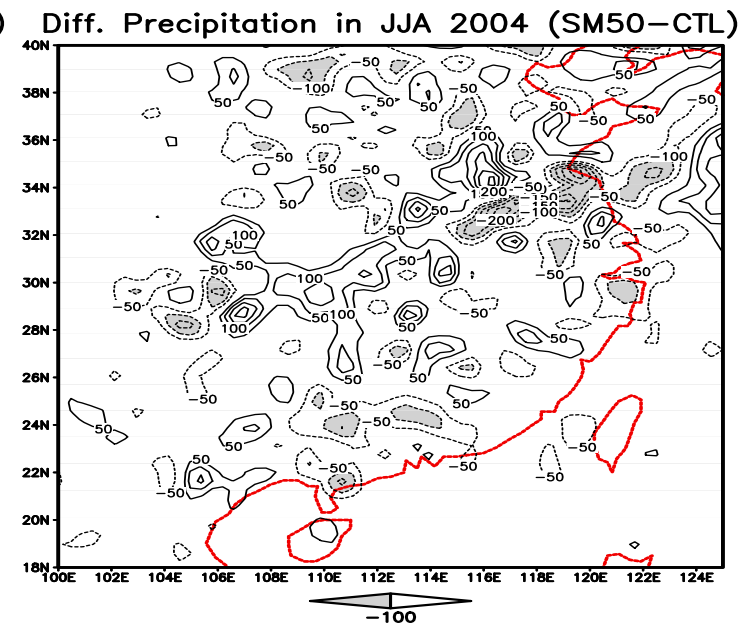

(b)

Figure 9. Seasonal precipitation differences of SM150-CTL (a) and SM50-CTL (b) in summer 2004 and 1999 (mm). Shaded is rainfall $>100 \mathrm{~mm}$ in (a) and $<-100 \mathrm{~mm}$ in (b). 


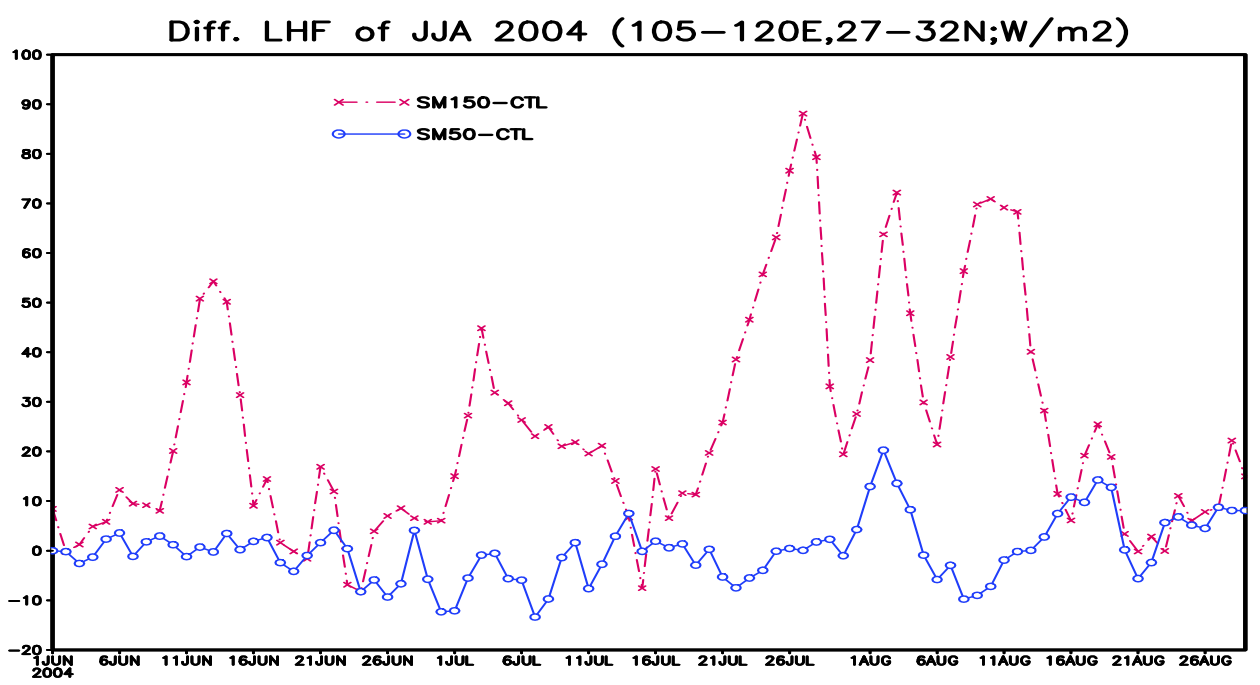

(a)

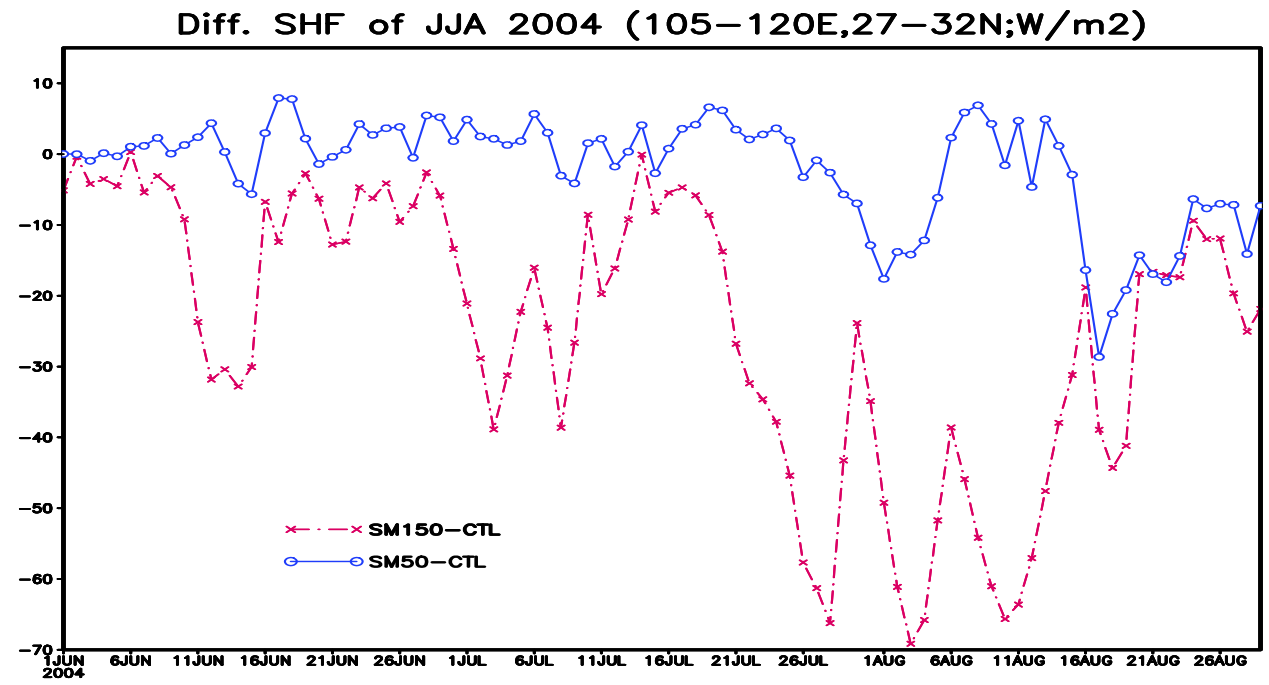

(b)

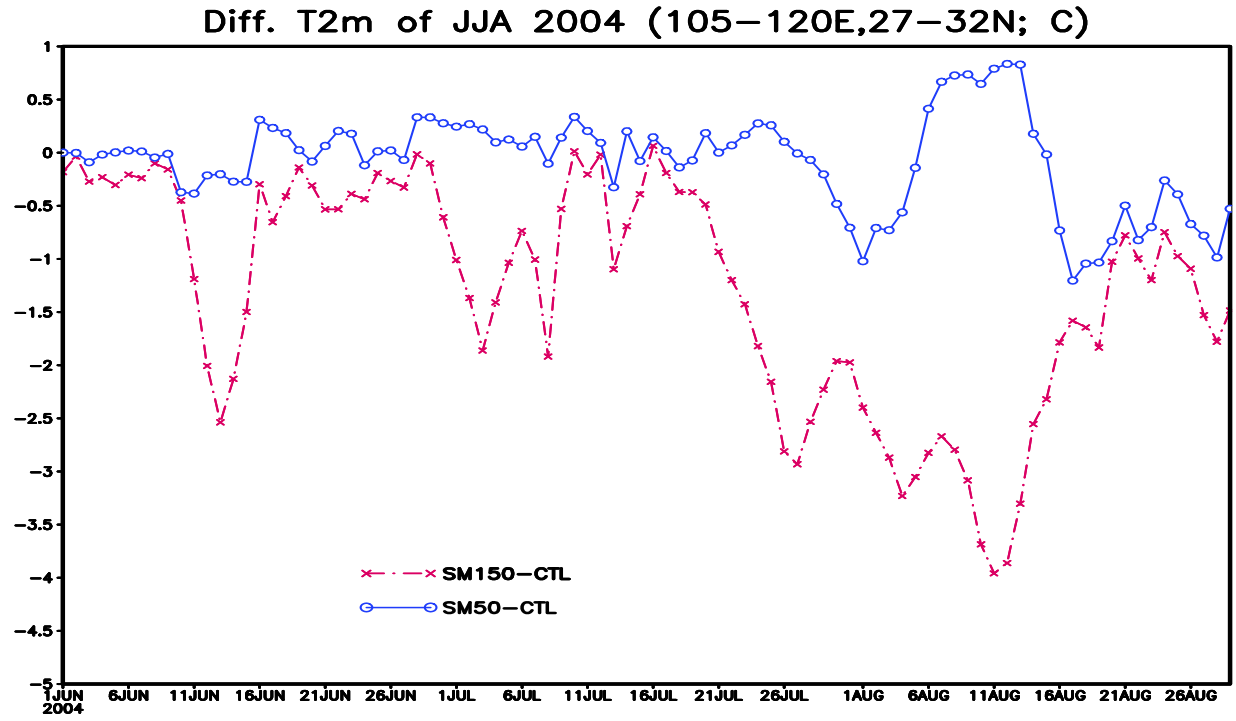

(c) 
Diff. FLSDD of JJA $2004(105-120 E, 27-32 \mathrm{~N} ; \mathrm{mm})$

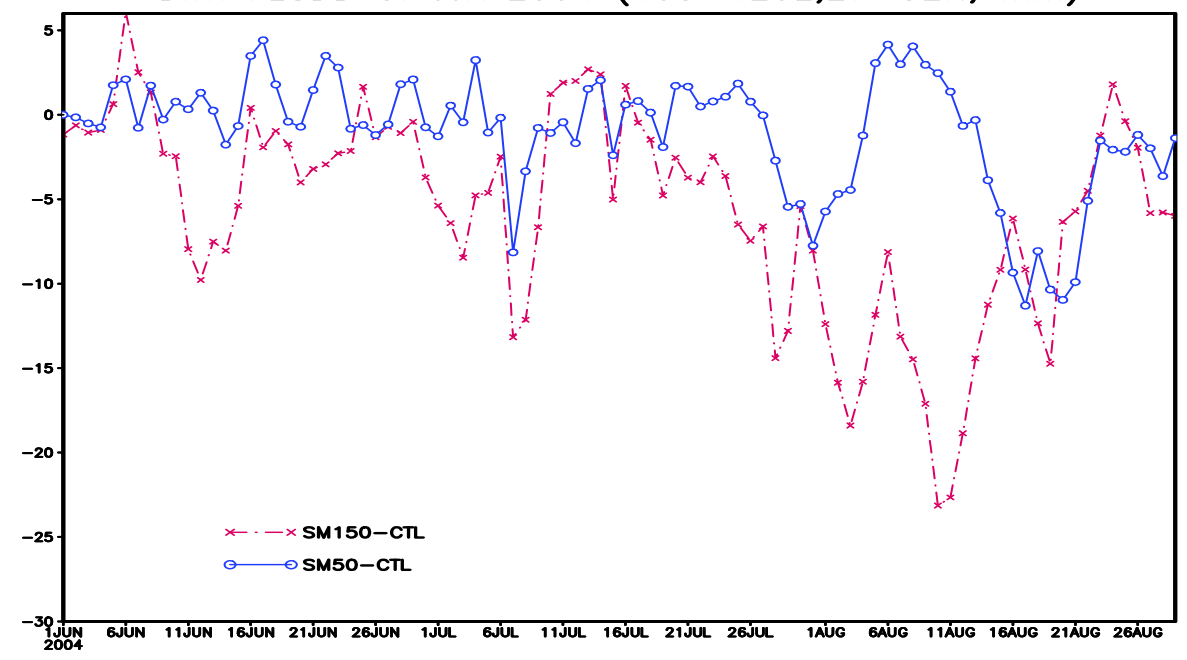

(d)

Diff. SSW of JJA $2004(105-120 E, 27-32 \mathrm{~N} ; \mathrm{mm})$

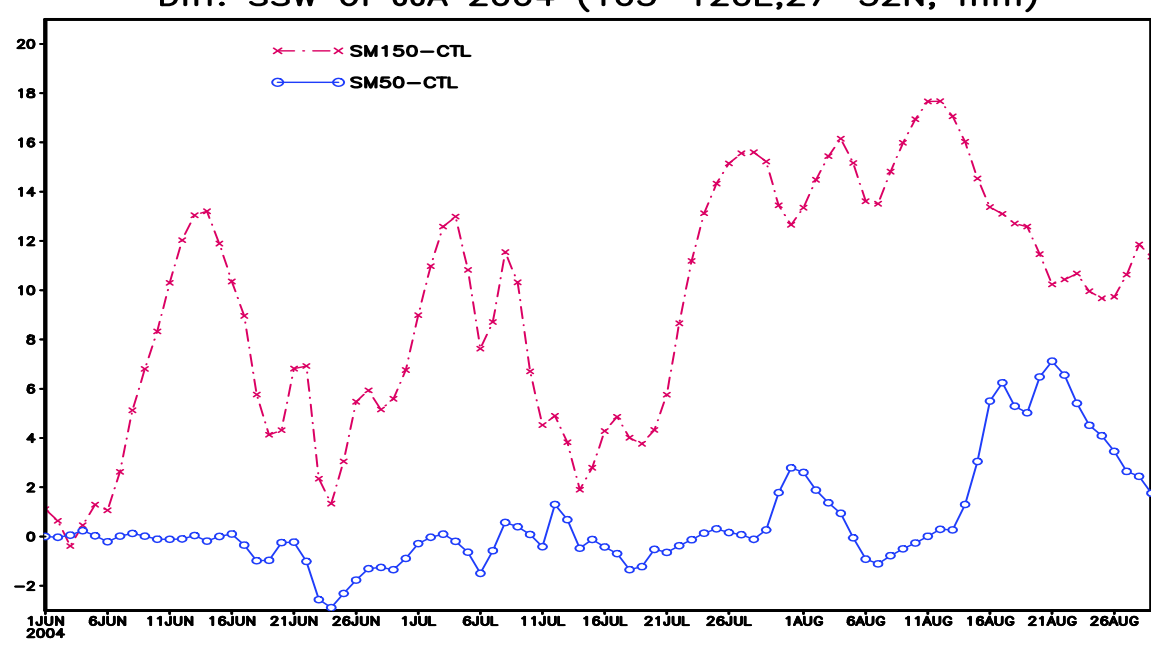

(e)

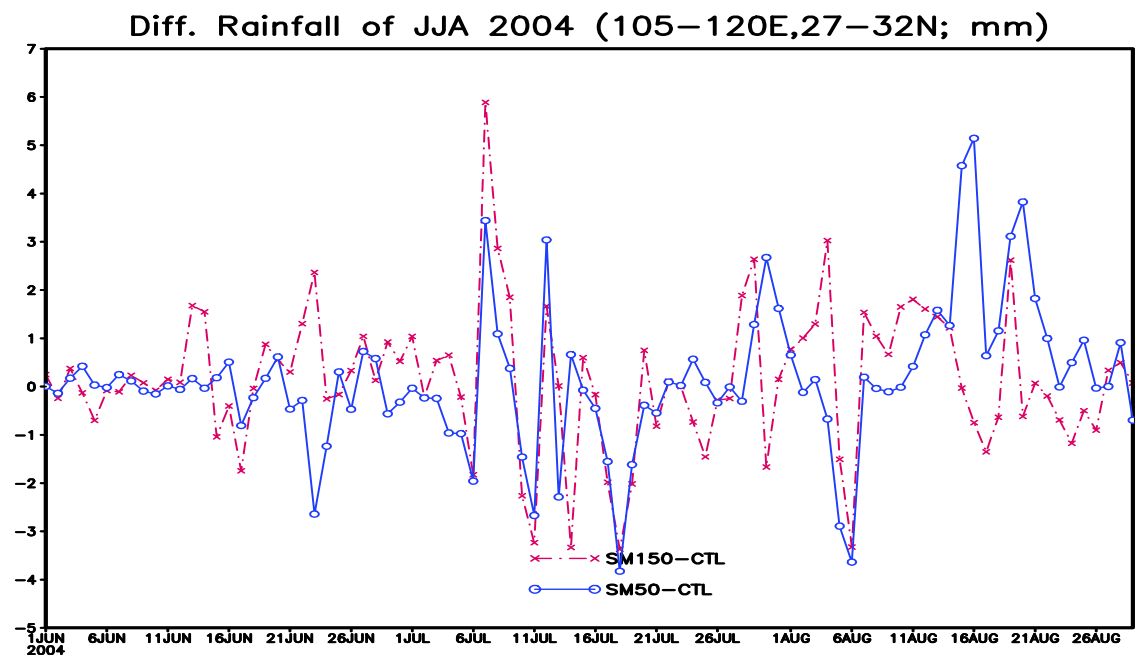

(f)

Figure 10. Same as Figure 5, but for the summer of 2004. 


\section{Summary and Discussion}

The effects of the initial soil moisture (SM) conditions over the Huaihe River Basin on the subsequent climate have been investigated with sensitivity experiments of the regional climate model. Results show that in both the abnormal flooding summer of 2003 and normal summer of 2004, the initial SM has significant effects on the subsequent climate of surface and atmosphere variables.

(1) The initial SM abnormal has significant effects on the subsequent surface climate. The initial "wet" ("dry") SM anomalies led to the increase (decrease) of latent heat flux and upper layer soil moisture, decrease (increase) of surface temperature and sensible heat flux. This general agrees with several previous results, but here the SM- wetting experiments show much significant effects than the SM-drying ones.

(2) The initial SM has certain impacts on the above atmosphere, especially at the mid-lower troposphere layers, such as the decrease (increase) of temperature with the wet (dry) initial SM. Particularly in SM150, the moisture is increased (decreased) at the lower (mid-lower) troposphere layers.

(3) Not totally opposite changes occur in SM50 and SM150 experiments, especially for the rainfall, which is related to the processes within atmosphere and need to study further.

This study focuses on the initial SM anomalies effects on the subsequent climate with the abnormal flooding and normal cases in summer 2003 and 2004. Some more cases (e.g., the abnormal drought cases along HRB) and further investigations are needed, such as processes involved and temporal efficiency of the SM impacts on precipitation. Additionally, although plenty of SM dataset are available from observation, model simulation or retrieval, great differences exist among them because of the differences in instruments, land-surface model and its initializing methods (e.g., Rodell et al. 2005) [16]. So the initialization of SM should be careful selected. The method used in study may be better to keep some internal consistent of the model system. And the half decrease/increase of SM is possible occur (but not extreme ones as the permanent wilting point and field capacity) in the nature, so the results present in this study have certain roles in the seasonal predictions, especially when the initial SM is abnormally wet.

Finally, the regional climate model is used, which is driven by the realistic representation of the large-scale atmospheric circulation, and therefore should be better to isolate the response of SM conditions. However, the results might be model-dependent; some other models should be applied for further investigation, for instance, combining the global climate model with the regional climate model.

\section{Acknowledgements}

The author is grateful for the valuable suggestions of Prof. D. L. Chen, Y. H. Ding and X. B. Zhang, as well as the comments of the anonymous reviewer. This work is jointed supported by the 973 projects (Grant No. 2007CB411505 and 2010CB951902).

\section{References}

[1] R. A. Pielke, G. E. Liston, J. E. Eastman and L. X. Lu, "Seasonal Weather Prediction as an Initial Value Problem," Journal of Geophysical Research, Vol. 104, No. D16, 1999, pp. 19463-19479. doi:10.1029/1999JD900231

[2] W. R. Wu, M. A. Geller and R. E. Dickinson, "The Response of Soil Moisture to Long-Term Variability of Precipitation," Journal of Hydrometeorology, Vol. 3, No. 5, 2002, pp. 604-613.

doi:10.1175/1525-7541(2002)003<0604:TROSMT>2.0.C $\underline{\mathrm{O} ; 2}$

[3] T. C. Yeh, R. T. Wetherald and S. Manabe, "The Effect of Soil Moisture on the Short-Term Climate and Hydrology Change-A Numerical Experiment," Monthly Weather Review, Vol. 112, No. 3, 1984, pp. 474-490. doi:10.1175/1520-0493(1984)112<0474:TEOSMO $>2.0$. $\mathrm{CO} ; 2$

[4] Y. Q. Liu, "Spatial Patterns of Soil Moisture Connected to Monthly-Seasonal Precipitation Variability in a Monsoon Region," Journal of Geophysical Research, Vol. 108, No. D22, 2003, p. 8856. doi:10.1029/2002JD003124

[5] E. A. B. Eltahir, "A Soil Moisture-Rainfall Feedback Mechanism, 1: Theory and Observations," Water Resource Research, Vol. 34, No. 4, 1998, pp. 765-776. doi:10.1029/97WR03499

[6] R. D. Koster, P. A. Dirmeyer, Z. C. Guo and Coauthors, "Regions of Strong Coupling between Soil Moisture and Precipitation," Science, Vol. 305, No. 5687, 2004, pp. 1138-1140. doi:10.1126/science. 1100217

[7] J. J. Xu, W. J. Shuttleworth and X. Gao, "Soil Moisture-Precipitation Feedback on the North American Monsoon System in the MM5-OSU Model," Quarterly Journal of Royal Meteorology Society, Vol. 130, No. 603, 2004, pp. 2873-2890. doi:10.1256/qj.03.192

[8] H. Douville, F. Chauvin and H. Broqua, "Influence of Soil Moisture on the Asian and African Monsoons Part I: Mean Monsoon and Daily Precipitation," Journal of Climate, Vol. 14, No. 11, 2001, pp. 2381-2403. doi:10.1175/1520-0442(2001)014<2381:IOSMOT $>2.0 . \mathrm{C}$ $\underline{\mathrm{O} ; 2}$

[9] Z. G. Ma, H. L. Wei and C. B. Fu, "Relationship between Regional Soil Moisture Variation and Climatic Variability over East China," ACTA Meteorological Sinica, Vol. 58, 2000, pp. 278-287. (in Chinese)

[10] C. H. Sun, W. J. Li and Z. Q. Zhang, et al., "Impact of 
Huaihe River Basin Soil Temperature and Humidity Abnormality in Pre-Winter and Sprint Time on the Anomalous Summer Rainfall and Its Application," ACTA Meteorological Sinica, Vol. 63, 2005, pp. 115-122. (in Chinese)

[11] Z. H. Lin, X. S. Yang and Y. F. Guo, "Sensitivity of Land Surface Model to the Initial Condition of Soil Moisture," Climate and Environment Research, Vol. 6, 2001, pp. 240-248. (in Chinese)

[12] Y. H. Ding, X. L. Shi, Y. M. Liu, Y. Liu, Q. Q. Li, Y. F. Qian, M. Q. Miao, G. Q. Zhao and K. Gao, "Multi-Year Simulations and Experimental Seasonal Prediction for Rainy Seasons in China by Using a Nested Regional Climate Model (RegCM_NCC). Part I: Sensitivity Study," Advances in Atmospheric Sciences, Vol. 23, No. 3, 2006, pp. 323-341. doi:10.1007/s00376-006-0323-8

[13] K. C. Chow, J. C. L. Chan, X. L. Shi and Y. H. Ding, "Time-Lagged Effects of Spring Tibetan Plateau Soil
Moisture on the Monsoon over China in Early Summer," International Journal of Climatology, Vol. 28, No. 1, 2008, pp. 55-67. doi:10.1002/joc. 1511

[14] M. Kanamitsu, W. Ebisuzake, J. Woollen, S. K. Yang, J. J. Hnilo, M. Fiorino and G. L. Potter, "NCEP-DEO AMIP-II Reanalysis (R-2)," Bulletin of Atmosphere Meteorology Society, Vol. 83, No. 11, 2002, pp.1631-1643. doi:10.1175/BAMS-83-11-1631

[15] S. Y. Hong and H. L. Pan, "Impact of Soil Moisture Anomalies on Seasonal Summertime Circulation over North America in a Regional Climate Model," Journal of Geophysical Research, Vol. 105, No. D24, 2000, pp. 29625-29634. doi:10.1029/2000JD900276

[16] M. Rodell, P. R. Houser, A. A. Berg and J. S. Famiglietti, "Evaluation of 10 Methods for Initializing a Land Surface Model," Journal of Hydrometeorology, Vol. 6, No. 2, 2005, pp.146-155. doi:10.1175/JHM414.1 